\title{
Utilizing Mobile Devices to Capture Case Stories for Knowledge Management
}

\author{
Jia Shen \\ Department of Information Systems \\ New Jersey Institute of Technology \\ University Heights, NJ, 07102 \\ jxs1866@njit.edu
}

\begin{abstract}
This study examines how the increasing number of new mobile devices that enable rich in situ information capture can be utilized to improve knowledge management practices. An ethnographic study is being conducted of a heating and cooling services company focusing on the exchange of case stories. With knowledge gained from this study a prototype system is being built that allows in situ multi-media data capture, and retrieval via the Internet. The proposed field study of this system will extend our understanding of how to effectively design for in situ multimedia data capture so that it is integrated in organizational processes.
\end{abstract}

\section{Keywords}

Knowledge Management, information capture, story

\section{INTRODUCTION}

With the increasing acceptance of the importance of intellectual capital for businesses and organizations, many information systems have been designed specifically to address knowledge management issues. Pioneers of information systems for knowledge management and organizational memory adopted a simple view of knowledge and a passive memory model. From this perspective, the design of collaborative systems is similar to database design. These early systems focused on categorizing information into fields for later reuse and retrieval (e.g. Answer Garden [1]). The result was that these systems only shared explicit information in strictly defined domains.

However, cognitive and social science studies show that knowledge is deeply contextual. Remembering is a constructive act, which not only requires active participation, but is also influenced by context [3]. Cognition can be better understood by looking at how people go about knowing what they know and the environment in which the knowing is accomplished [6]. Applying these perspectives, researchers have started to abandon the view of organizational memory as repositories of experience objects, and suggest considering organizational memory as both object and process [2]. A new generation of knowledge management is also being proposed to "grow beyond managing knowledge as a thing to also managing knowledge as a flow" [10]. However, how exactly these perspectives should be realized in the design of knowledge management systems has not been clearly articulated.

Another trend we see in recent years is that more and more mobile consumer electronics have entered our lives, such as cell phones, digital cameras and PDAs. However, the widespread adoption of such mobile and personal communication devices has not resulted in them being integrated into organizational knowledge management practices. Clearly, such technologies provide new opportunities and challenges.

Mobile computing technology has the potential to become an important part of the knowledge management process not only because of its ability to access information anytime, anywhere; but its ability to capture information in situ. Rich context can be captured: physical environment, organizational, social, and cultural context [4], as well as rationale in problem solving process, which can be utilized to enhance tacit as well as explicit knowledge transfer. This research aims to increase our understanding of how to design systems that effectively use rich data captured in situ to enhance knowledge transfer. With the move from the provision of Simple Messaging Services (SMS) for text exchanges on mobile phones, to Multimedia Messaging Services (MMS), the need for such design and usability research is becoming increasingly important.

\section{METHODOLOGY}

\section{Unit of Analysis}

The unit of analysis in this research is what we refer to as "case stories". We define a case story as a message that tells the particulars of an occurrence or course of events that is directly related to work process. Similar to stories, a case story is told for a particular purpose. Different from other forms of stories, such as jokes, news, or notifications, 
case stories focus on work process experiences. Such case stories have been used to share informal information; transfer tacit knowledge; share organizational culture and norms; help form communities of practice; and catalyze organizational change. Orr's pioneering research, which examined Xerox photo-copier repair technicians in 1986, showed how the exchange of "war stories" could help a community of practice diagnose problems, circulate information, and celebrate identity [8]. The "war stories" that Xerox repair technicians exchanged can be considered as typical case stories. Despite Orr's work influencing the development of a number of mobile systems, understanding how to design for rich case-story data exchange is limited.

\section{Tools For In Situ Rich Data Capture}

Historically case stories have been captured after the event in the form of text case notes. In this research, a significant proportion of rich in situ case-story data will be captured by the use of mobile phones for voice messaging and digital cameras for still images. Both voice and still image are natural means for capturing fleeting thoughts and events. Storytelling with digital photos have been explored in a number of studies [9], and augmenting photo with audio has gained increasing interest [5]. Although several models of digital cameras that enable audio recording exist, our exploratory research requires more flexibility and thus initially we are using separate tools for voice and image capture.

\section{Procedure}

In situ case story capture and management is explored in this research through three phases of the usability engineering lifecycle. They are presented in a linear fashion for clarity, but the activities described are carried out iteratively.

Theoretical framework development and requirements analysis: User observations, and interviews with seven technicians, four secretaries, managers, drivers, and a small number of customers of a heating, and cooling services, company are being conducted. The company provides fuel, house boiler and air conditioner repair, and maintenance service to about 3000 customers. A significant proportion of the technicians' activities can be described as mobile knowledge work, and a significant proportion of the office activities support the mobile technicians. A theoretical framework is being developed to describe how voice and image capture technologies can be used to support the capturing, archiving, and sharing of case stories among technicians, secretaries and customers.

System instantiation and iterative prototyping: At present we are developing basic infrastructure for data capture and management. A Voice-XML gateway linked to a web-server currently enables subjects to record and retrieve case stories. We are working on the simple uploading of photos via wireless transmission, and a usable web interface for the retrieval of case-story related sounds, images, and text. Once the basic system [7] is in place, a small pilot study will be conducted using two technicians and one of the secretaries. We are also exploring the use of MMS, which does not appear to be practical for our research at this stage.

Evaluation: Detailed evaluation of the prototype system will be carried out by a field trial of the technology. Assessments made will include: measuring technician and customer satisfaction; measuring work process outcomes such as return service calls and post service office phone time; service call effectiveness; and semi-structured interviews with technicians, secretaries, managers, and customers.

\section{STATUS \& CONTRIBUTIONS}

Preliminary investigation suggests that the proposed approach will have significant benefits for the company being studied. This study is among the first to integrate information capture in situ into organizational knowledge management processes. It suggests that future advances in MMS technologies will result in them being an integral part of mobile work practices. This research should enhance our understanding in the design of a new generation knowledge management systems, which utilizes mobile technology.

\section{ACKNOWLEDGEMENTS}

I would like to thank my advisor Dr. Quentin Jones for guidance and support, Steve Whittaker and Roxanne Hiltz for discussion and comments, and MacKinney Oil Company for allowing us to conduct the field study.

\section{REFERENCES}

1. Ackerman, M.S., Augmenting the Organizational Memory: A Field Study of Answer Garden. Proceedings of CSCW, 1994.

2. Ackerman, M.S. and Halverson, C., Considering an Organization's Memory. CSCW, 1998.

3. Bartlett, F.C., Remembering: A Study in Experimental and Social Psychology. 1932, Cambridge, England: The University Press.

4. Dourish, P., Seeking a Foundation for Context-Aware Computing. Human-Computer Interaction, 2001. 16.

5. Frohlich, D., Adams, G., and Tallyn, E., Augmenting Photographs with Audio. (Hewlett Packard Labs). Personal Technologies, 2000. 4: pp. 205-208.

6. Hutchins, E., Cognition in the Wild. 1995: MIT Press.

7. Jones, Q., System and Method for the Storage, Management and Sharing of Spatial-Temporal Based Information. United States Patent Application Numbers 90/898190 and 60/217089, 2000, 2001.

8. Orr, J., Narratives at Work: Story Telling as Cooperative Diagnostic Activity. CSCW, 1986.

9. Shen, C., Lesh, N.B., Moghaddam, B., Beardsley, P.A., and Bardsley, R.S., Personal Digital Historian: User Interface Design. CHI 2001, 2001.

10. Snowden, D., Complex Acts of Knowing: Paradox and Descriptive Self-Awareness. Special Edition Journal of Knowledge Management, 2002. 6(2). 
